\title{
EL PARLAMENTO EN EL ESTADO DEL CAPITALISMO AVANZADO: SITUACION Y PERSPECTIVAS
}

\author{
Por Carlos DE CABO MARTIN \\ Catedrático de Derecho Político
}

El planteamiento de la temática parlamentaria en la forma que se establece en el título de este trabajo, hace referencia a dos tipos de cuestiones ciertamente relacionadas pero también y secuencialmente diferenciadas: En primer lugar se intenta dar una respuesta que explique la actual situación de los Parlamentos; en segundo lugar se trata de cuestionar el papel y función que pueden hoy desempeñar los Parlamentos en las sociedades especificas que se contemplan y en relación con unos determinados objetivos.

I.-Explicaciones a la crisis de los Parlamentos.

Hay que recordar, aunque sea brevemente, que la historia de los Parlamentos y de su supuesto teórico básico, la representación, no ha sido una historia pacífica. $Y$ conviene tenerlo en cuenta porque, como veremos, algunas de las críticas modernas tratan "de presentar como nuevos, intrumentalizándolos, hechos y argumentos que, en su versión, han roto el ideal de referencia, cuando lo cierto es que ese ideal nunca existió. A efectos, pues, de mantener la memoria histórica, debe señalarse que desde la Revolución Francesa(1) se dibujan dos líneas críticas que se prolongan con posterioridad: 
a) Una es la que se basa en la idea de ficción jurídica. La representación y el Parlamento son una ficción jurídica. El elegido no representa a los electores, que no transmiten poder alguno, ni el Parlamento representa a entidad colectiva alguna que tenga una voluntad preexistente $y$, por consiguiente, representable por la Asamblea. Por eso el sistema representativo se considera una pura "metáfora" en el lenguaje de Roger-Collard.

Como es conócido el argumento fue utilizado después por la dogmática alemana para, a partir de la elaboración de la concepción de la personalidad jurídica del Estado, sustituir la teoría de la representación por la del órgano(2), con la finalidad política clara de potenciar el principio monárquico frente al representativo, siguiendo esa característica general de la cultura jurídica y política alemana de reducir los principios de la Revolución Francesa a una virtualidad distinta de la original. La elección no hace sino designar un órgano del Estado, lo que tenía como consecuencia inmediata la ruptura de toda relación electores-elegidos con posterioridad a la elección(3). La idea será recogida por Kelsen que niega también la naturaleza jurídica de la representación, señalando, no obstante, que tal "ficción" ha permitido "legalizar el parlamentarismo bajo el aspecto de soberania del pueblo y mantener el movimiento político realizado bajo la presión de la idea democrática, en niveles sensatos»(4).

b) Otra es la que entiende que, justamente, la representación funciona como un antídoto para la democracia. Tiene su manifestación primera y más expresiva en la inicial formulación de Rousseau: el soberano no puede ser representado más que por sí mismo. La voluntad general no es susceptible de representación. La democracia no puede ser más que democracia directa. Aunque, somo se sabe, el propio Rousseau introdujo importantes correcciones, la crítica radical por él iniciada ha tenido con posterioridad una doble línea de desarrollo.

Por una parte, se rechazo el sistema representativo en base a algo que en 1.791 afirmara Barere: el gobierno representativo es aristocrático por naturaleza. Y lo cierto es que, desde los teóricos de las élites a Carl Schmitt, el argumento se ha repetido: el sistema representativo consagra frente a la democracia de masas la soberania de las minorias depositarias de las dos exigencias de la burguesía liberal: propiedad e instrucción. En relación con ello son bien conocidos los análisis de Gaetano Mosca acerca de la dependencia de los diputados de los grandes electores, de los miembros influyentes de los distintos comités, de los diversos intereses sectoriales y locales, etc.

Por otra, no cabe desconocer que los presupuestos de Rousseau están, en gran medida, en el origen del inicial rechazo anarquista de la representación y las Asambleas (anuque se enriquezca con posterioridad a través de la crítica a la realización del principio representativo y a sus efectos) así como de los comienzos de la crítica marxista; señalará Marx, en 
efecto, en la Crítica a la Filosofía del Estado de Hegel, cómo el supuesto representativo separa idealmente lo que realmente es inseparable: lo político y lo social. El hombre de la sociedad civil en situación concreta de clases, desaparece. Queda sólo el hombre político, a través de cuya consideración la igualdad abstracta sustituye a la desigualdad concreta. El Parlamento se constituye así en el vehículo de disolución de la sociedad civil y de transustanciación del hombre real, desigual, en el ciudadano igua(5). Galvano della Volpe ha mostrado el origen roussoniano de esta concepción marxista de la igualdad. Y Daniel Guerini la funcionalidad del mecanismo: frente al absolutismo permitía afirmar que el poder procedia del pueblo y frente a la pretensión de éste de ejercerlo realmente por sí mismo actuaba como filtro depurador y aislante(6).

Si ésta es, esquemáticamente expuesta, la crítica clásica, la crítica moderna en torno a los parlamentos, aunque inspirada como se apuntó y tendremos ocasión de comprobar por buena parte de argumentos clásicos, responde básicamente a un hecho que habitualmente se admite sin discusión. La situación actual de los Parlamentos muestra una situación de crisis a un doble nivel: a un nivel político, que se manifiesta en una pérdida de poder de los Parlamentos y a un nivel técnico que se manifiesta en una pérdida de eficiencia de las asambleas. El hecho está, como es bien conocido, en el centro de la discusión teórico-política de nuestro tiempo. Me parece que no es necesario subrayar, cómo la dificultad e importancia del tema, así como la multiplicidad de enfoques y su constante replanteamiento por la literatura especializada, hacen extremadamente complicado no sólo el intento de aportaciones al mismo sino el de ofrecer un estado de la cuestión.

En cualquier caso y optando por la claridad, que considero un valor de preferencia siempre pero en este caso especialmente, $y$, sobre todo, en base al específico emplazamiento en que trato de situarme, se podrian, a mi juicio, distinguir las siguientes corrientes metodológicas a través de las cuales se trata de dar una respuesta a la precitada crisis de los Parlamentos:

1.- Una corriente de corte positivista que trata de explicar la crisis de los Parlamentos actuales en base, fundamentalmente, a su comparación con un "modelo" de Parlamento, que resultará ser un modelo ideal-aunque con frecuencia se quiera hipostasiar este modelo en el Parlamento liberal $-y$ que en consonancia con ello da explicaciones simples, en el sentido de privilegiar o atribuir a un solo elementos la causa de la crisis.

De acuerdo con este planteamiento metodológico, más o menos explícito pero siempre presente, la crisis de los Parlamentos actuales debe explicarse en virtud de la quiebra de algunos de los supuestos que daban vida al modelo ideal (liberal), en un doble orden: 
a) En el orden de los principios:

1). El supuesto básico de la representación, expresado por Sieyés-se afirma-era el siguiente: «el derecho a hacerse representar no pertenece a los ciudadanos más que a causa de las cualidades que les son comunes y no de las que les diferencian". Pues bien, es claro-se dice-que este supuesto sólo se verifica en el Estado liberal en cuanto únicamente se ocupaba del mínimo número de asuntos comunes a todo ciudadano. Por el contrario, el Estado actual interviene no sólo en los asuntos comunes sino en aquellos que determinan la propia individualidad y especificidad de cada uno en su situación y problemática concreta.

Es la postura de Forsthoff. La problemática del Parlamento moderno, según Forsthoff, se puede formular asi: el Parlamento moderno debe cumplir, idealmente, dos funciones básicas: legitimar democráticamente el sistema y poseer la suficiente capacidad de actuación material y técnica en su campo específico que es la legislación. Ambas funciones, señala Forsthoff, en el modelo liberal eran compatibles porque ambas se desenvolvían únicamente en el ámbito político y, en concreto, la legislación se refería fundamentalmente a concretar principios, ordenar creencias, reglar los grandes intereses comunes. En el Estado actual, sin embargo, la segunda función, la función legisladora, es técnica, especializada y múltiple. En puridad, sólo la deberán hacer los expertos. Pero entonces se plantea el gran dilema: o sólo se elige a los expertos con lo que se in. cumple la necesaria función de legitimación o lo que realmente se hace: para cumplir esa función se utiliza un procedimiento de selección que no garantiza en absoluto la realización, con garantías técnicas suficientes, de la función legislativa. Tras rechazar la vinculación de los expertos al Parlamento porque supondría una dependencia de los diputados respecto de aquellos a quienes les solicita la información, lo que exigiría unas específicas condiciones de "lealtad" que trasladaria en cierta forma el problema a la selección de los expertos, termina proponiendo reservar al Parlamento solamente las normas políticamente relevantes y abandonar las demás y su desarrollo al Gobierno(7). Es clara la remisión de Forsthoff al Parlamento liberal más como modelo ideal de referencia que como apelación histórica real, pues es conocido y se apuntaba antes en la crítica clásica, cómo uno de los defectos que se achacaban al Parlamento liberal era estar atravesado por los intereses locales y sectoriales. Aparte de que la perspectiva de Forsthoff no es tanto fortalecer el Parlamento como el Estado, lo que exige como primera via-según él-el fortalecimiento del ejecutivo.

2) Se ha producido una desvirtuación del principio representativo. El advenimiento del sufragio universal ha roto la relación representantesrepresentados existente con anterioridad. 
El número creciente de electores representados por cada elegido disuelve la relación de representación, pues no es posible representar jurídicamente a la nación (único denominador común de millones de indivíduos) y sociológicamente a cada uno de ellos en su individualidad. Sartori ha señalado en esta línea argumental, una relación inversa entre la extensión y la intensidad de la representación, en cuanto que en la medida en que representa a todos, el diputado no representa a nadie.

Ciertamente la imposición del sufragio universal tuvo una serie de efectos importantes a los que después aludiremos, pero precisamente éste que señala Sartori es el más discutible. Aparte de que el argumento es notablemente grosero (atribuir al número la modificación de la naturaleza jurídica de la representación), hay que recordar de nuevo que la discusión sobre si existe o no relación de representación entre electores y elegidos no es algo que pueda presentarse como el hecho más característico de los Parlamentos actuales tal como se vió con anterioridad.

Más interés tienen las posiciones que tratan de contraponer Parlamento y democracia. Ello exige una mínima disgresión histórica.

Se ha observado, desde presupuestos estrictamente empíricos que así como las distintas leyes electorales que iban ampliando el derecho de sufragio pueden permitir establecer con alguna fijeza las diferentes etapas del proceso democratizador, el acceso al Parlamentarismo no ha tenido una manifestación secuencial tan cristalizada. Ello se relaciona con la idea de que el Parlamentarismo como régimen político es más un resultado práctico que fruto de una elaboración teórica; porque, efectivamente, los supuestos teóricos que sirven de base organizativa al Estado moderno se sitúan en la alternativa que representaban Montesquieu y Rousseau; el uno llevaba a la separación relativa de poderes en forma próxima al Presidencialismo y el otro conducía a la confusión de poderes característica del régimen de Asamblea. Pero de ninguna manera puede decirse que el régimen Parlamentario se contenga en uno $u$ otro.

Pero lo que aquí interesa destacar es que el Parlamentarismo precede históricamente a la democracia. Salvo en algún caso (como en Suecia donde las mismas transformaciones sociales y económicas fueron la causa del doble movimiento hacia el Parlamentarismo y hacia la democracia como ha señalado Fusilier) la instauración del Parlamentarismo ha precedido al reconocimiento del sufragio universal, movimientos ambos que tienen un origen y una dinámica independientes como ya en su momento señalara M. Guetzevich; lo que realmente sorprende es el asombro que este "descubrimiento" produjo en autores como Fusilier, que al citar, al comienzo de su clásico estudio sobre las Monarquias Parlamentarias, la afirmación de Guetzevich, la considera "frappante", así como en Prelot, que llega, incluso, en la conocida introducción al libro de Fusilier, a atribuirse la originalidad del hallazgo en su "Precis", donde sostiene esta 
tésis-dice- "contra la opinión de la mayoría". Y sorprende, porque pertenece a un saber histórico-político nada profundo el conocimiento de que el proceso representativo que conduce al Parlamentarismo es creación del movimiento burgués, mientras que la lucha por la democracia, que en gran parte se concreta en este periodo histórico en la lucha por el sufragio universal, es producto del movimiento de masas que empieza a desarrollarse más tarde y comienza a adquirir perfiles definidos en 1.848 .

Pues bien, aceptada la línea de separación entre Parlamentarismo y democracia, lo que se viene a sostener por la postura que analizamos es, precisamente, su radical incompatibidad, hasta el punto de que se entiende que la "crisis permanente" del gobierno parlamentario en general y de los Parlamentos en particular, procede de la winadecuación de la estructura tradicional de esta forma de gobierno para incorporar y realizar los principios en los que un ordenamiento debe inspirarse para poder definirse como democráticos(8). En el Gobierno Parlamentario-se dice-la ley de oro es que sólo el Parlamento expresa la voluntad y el interés general y, desde esta lógica, instituciones como el referendum abrogativo, el control de constitucionalidad de las leyes, el poder de disolución de las cámaras o las atribuciones al ejecutivo basadas en algo que en sí no es un concepto jurídico como es el principio de la mayoría, no son sino la completa desvirtuación del régimen representativo. Y los intentos hechos para convertirlo en democrático lo han desnaturalizado o en un sentido (acercándolo al régimen asambleario) o en otro (acercándolo al régimen plebiscitario).

En cualquier caso y pese a la aparición de nuevos argumentos, lo cierto es que la afirmación de que la representación parlamentaria no es identificable con, ni conduce a, la democracia se encuentra y con más radicalidad sostenida en lo que antes llamábamos crítica clásica(9).

3) El argumento sobre la partitocracia.

La aparición, intervención y monopolización de la vida política por los partidos políticos se ha interpuesto en la relación directa, característica de la representación liberal, elector-elegido, destruyendo esa relación. Tanto antes de las elecciones decidiendo los candidatos, como durante éllas por las características que contemporáneamente tienen las campañas electorales, como tras las elecciones con la formación y funcionamiento de los grupos parlamentarios, el partido es el único protagonista. Las decisiones del Parlamento son realmente decisiones de los partidos y, aún, dado el proceso irreversible de oligarquización, de la cúspide de los mismos.

Ciertamente el tema de los partidos en las democracas modernas es mucho más complejo que el que presenta esta simplificación interesada; pero dentro de las posiciones que atribuyen a los partidos una responsabilidad importante en la crisis de los Parlamentos, se encuentran perspecti- 
vas mucho más matizadas: así se hablará de las consecuencias negativas de la fragmentación partidista en los espacios básicos del espectro político, se especificará la crisis en base a la actuación de determinados partidos y en concreto al comportamiento de los partidos en el poder(10) etc. Interesa, no obstante, dejar aqui constancia de aquella perspectiva porque, de alguna forma, sobre los demás aspectos de la problemática partidista volveremos y porque, además, la comparación con la crítica clásica (en la que señalábamos cómo ya antes de la aparición como organizaciones permanentes de los grandes partidos de masas, se atacaba la representatividad del parlamento al afirmarse que los diputados estaban en manos de los grandes electores, comités locales, intereses de diverso tipo, etc.) pone de manifiesto la continuidad y real naturaleza de un pensamiento antidemocrático, aunque a veces trate de hablar en nombre de pretendidas purezas democráticas.

b) En el orden de los hechos.

1) Ha pasado el tiempo-dirá Prelot-de los intermediarios políticos. Las técnicas modernas (medios de comunicación, sondeos de opinión, etc.) permiten la comunicación directa poder-pueblo. La técnica elimina materialmente al intermediario que Rousseau descalificara inte: lectualmente. Cada vez más-dirá Labriola-la representación es deudora de los medios de comunicación (en régimen por otra parte de monopolio o de oligopolio) con lo que la representación se reduce a la forma de organizar y obtener el consenso.

2) La composición de los Parlamentos muestra desde la práctica, la falsedad de los supuestos representativos, tanto por la sofisticación a que se ha llegado en la manipulación de las elecciones a través de la conjugación adecuada de los diversos elementos que componen los sistemas electorales, como, y quizás sobre todo, por el problema que se estima más importante de los Parlamentos actuales: la no representación de los «intereses" verdaderamente actuantes y movilizadores. Se afirma así, que una adecuada articulación parlamentaria de la representación de intereses es la única via para resolver tanto la crisis de representación real de los parlamentos como la crisis política o de poder(11).

3) Se afirma, finalmente, que la crisis de los Parlamentos deriva de su ineficiencia. Es un supuesto más de absolescencia. Ni por su organización y funcionamiento se acomodan al acelerado ritmo que alcanzan hoy las evoluciones de la coyuntura, ni por su composición y dotación cuentan con el equipaje adecuado para enfrentarse con garantías de eficacia a la complejidad y tecnificación que han experimentado los procesos socioeconómicos en que el Estado de nuestros días está obligado a intervenir. Es la conocida postura tecnocrático-autoritaria.

2.-Una segunda corriente, que si bien por su pretensión de análisis 
más complejos, vocación parlamentaria y carga ideológica reclama un tratamiento diferenciado, lo cierto es que no supone sino una variante de la anterior y de sus presupuestos más profundos.

Podría caracterizarse de la siguiente forma:

a) Por lo que se refiere al análisis de la actual situación de los Parlamentos, se pone el acento en la necesidad de relacionarla con las transformaciones institucionales, estatales, sociales e internacionales ocurridos en las modernas sociedades industriales. En este sentido afirma Lebriola(12) que "no cabe considerar al Parlamento al margen de la interrelación con la posición y funciones atribuidas a los otros órganos situados en el vértice del ordenamiento, porque el Parlamento no es una variable independiente del sistema del poder político"... «Todas las instituciones han cambiado: el gobierno extendiendo sus atribuciones, la corte constitucional aumentando sus competencias a través de una jurisprudencia interpretativa que invada la función legislativa, la judicatura que hace de su independencia un uso discutible, todo lo cual repercute en el Parlamento que ve contínuamente mermadas sus atribuciones pues permanece sin cambiosw(13). Pero ello no puede suponer reducir el problema a adecuar el Parlamento a las nuevas competencias, sino entender que sufre, aunque de manera especifica, la crisis general de las instituciones que, a su vez, tiene su origen en el cambio de una sociedad que no se puede ordenar mediante las reglas y principios que fueron elaborados en y para una distinta fase histórica(14). Entre estos cambios se destaca-R. Ballardini(15) - la transformación experimentada en algunos poderes o la aparición de otros inexistentes en la sociedad liberal, tales como sindicatos, partidos, banca, televisión, administración económica, organismos internacionales, etc., lo que hace que las tradicionales limitaciones del sistema representativo (el que amplios sectores de poder no se constituyan con arreglo a él como ocurre con el Efército, la judicatura, la Administración, etc.) no sólo aumentan cuantitativa sino cualitativamente, pues progresivamente un número de funciones cada vez mayor y más importante queda fuera de los supuestos representativos.

b) Por lo que se refiere a los objetivos, su propuesta reformadora parte de afirmar la democracia parlamentaria como fin y busca la potenciación del Parlamento, pero con el límite de que no rompa el equilibrio y la racionalidad correspondiente al sistema representativo.

Se afirma, en efecto, que a consecuencia de las contradicciones antes señaladas-entre viejos principios y nuevas realidades-los necesarios equilibrios cada vez más se buscan y tienen lugar fuera del sistema que sufre con mayor evidencia una verdadera crisis de representación y legitimidad. Por eso-señala Labriola-lo primero que hay que decidir es si se sigue con la lógica del sistema anterior o se propone otro sistema alternativo. $Y$ tras descartarlo, se reafirma el valor de la democracia representa- 
tiva, cuyo respeto exige el respeto a su lógica institucional y ésta, a su vez, incluye un equilibrio entre las instituciones y los poderes de forma que una protagonización del Parlamento no sería aconsejable(15). Aparte de otras medidas más concretas para recuperar el papel funcional del Parlamento, prácticamente las únicas vías que se proponen son, por una parte, encomendar al Parlamento las decisiones más generales y a largo plazo y dejar al Gobierno las decisiones sectoriales e inmediatas, para resolver-dice Enzocheli(16) - la contradicción básica que atraviesan los Estados actuales de tener que actuar en ambos niveles, y, por otra, la coordinación de la vía parlamentaria con formas de democracia directa, especialmente el referendum(17).

Resulta así, que esta segunda tendencia puede considerarse vinculada a la primera en cuanto coinciden en un análisis superestructural, en su referencia al "modelo» (es particularmente intenso en este último el peso que en ella tiene el mito de la división de poderes) y en su perpectiva empírica, pues la pretendida complejidad del análisis se resuelve finalmente en una complejidad puramente descriptiva.

3.-Un tipo de explicaciones que se basa en un planteamiento específicamente teórico: estudia la situación actual de los Parlamentos a través de su interrelación con los demás elementos de una totalidad compleja de la que forman parte y a partir de la cual (de su forma de inserción el ella) cada uno cobra su peculiaridad.

En base a este planteamiento debe hacerse ya una primera precisión. El problema de la crisis de los Parlamentos no se refiere, o se refiere de distinta manera, a las formaciones económico-sociales del capitalismo periférico. En efecto, como ha señalado H. R. Sonntag(18), el característico proceso de acumulación de este tipo de sociedades viene determinado por la "bidireccionalidad" (economía metropolitana y economía nacional) lo que se manifiesta en el ámbito político en una serie de hechos apuntados por Tilman Evers(19): frente al Estado burgués del "Centro" que garantiza la reproducción y expansión del capital nacional, el Estado situado en el espacio económico periférico garantiza la existencia y expansión de los intereses del capital extranjero, to que implica resolver los desajustes y contradicciones correspondientes para articular las exigencias del mercado mundial y las características y estructuras de la producción local. Y todo ello conviviendo, también contradictoriamente, con una ideologia nacionalista (que habla del Estado Nacional soberano) que con frecuencia hubo que desplegar para utilizar sus virtualidades en el momento anterior de nación emergente. Resulta así-señala T. Evers-que el problema básico del Estado periférico es transformar una hegemonía externa en interna. Y para ello, los canales "clásicos"-partidos, Parlamento-no sirven y hay necesariamente que deformarlos. De una parte, porque la fracción dominante (la burguesía externa) se encuentra incapacitada, por su implanta- 
ción social escasa, para ganar unas elecciones mínimamente libres y limpias, por lo que la manipulación y el fraude electoral son inevitables; de otra, porque para que los intereses divergentes de las diversas clases 0 fracciones puedan "parlamentarizarse", tienen que ser de alguna manera mensurables, tener un mínimo de identidades del que carecen las clases en pugna en el capitalismo periférico; por ello, igualmente, las clases dominadas no caben en el Parlamento en proporciones aunque sólo sean relativamente próximas a su fuerza real, porque pueden desencadenar una dinámica que acabe con el sistema. El resultado-y esto parece generalizable-es un Estado permanente de excepción(20).

Por eso no tiene sentido plantearse el tema de la crisis de los Parlamentos en este tipo de sociedades desde los mismos esquemas sin incurrir en graves falsificaciones(21). Todo lo cual no hace sino confirmar la tesis apuntada en otra parte(22) de que, siguiendo el sentido general del desarrollo científico, la ciencia política es en gran medida una ciencia de y para lo que, sin mucha precisión literal pero con un contenido que se sobreentiende con claridad, se suele llamar Occidente.

Una segunda precisión deriva de aquel planteamiento metodológico: la actual configuración del Estado "Occidental", la decadencia de las Iibertades $y$, específicamente, la decadencia o transformación operada en los Parlamentos, hay que ponerla en relación con el proceso de desarrollo de la "totalidad compleja" del modo de producción capitalita y en concreto con la fase actual del capitalismo monopolista en los paises dominantes.

Ello implica, por una parte, salir de la perspectiva que conllevaban buena parte de las posturas anteriores atribuyendo la crisis de los Parlamentos a explicaciones "simples"; por otra, entender que no cabe acercarse al estudio de la situación actual de los Parlamentos sin considerar las nuevas formas de relación entre Estado y sociedad, entre lo político y lo económico, en definitiva, la específica configuración del Estado en los paises de capitalismo dominante. Generalización que puede servir a los efectos de este trabajo pero que no supone ignorar que cada sistema político es especificamente nacional como lo es asi mismo la lucha de clases, mientras el capitalismo es prevalentemente internacional, si bien formado como es sabido por elementos desiguales, que se insertan de manera peculiar, peculiaridad que de nuevo incide en el sistema político.

Pues bien, exceptuando alguna postura-por otra parte en revisióncomo la tradicional de los partidos comunistas con su equívoca concepción del Estado como Estado instrumento, que en realidad llevaba a la consideración de su neutralidad, los nuevos intentos tratan de percibir las relaciones estructura-superestructura en forma mucho más compleja. Aunque las vías de investigación y las correspondientes hipótesis son en este momento múltiples, existe un relativo acuerdo en considerar que el Estado no es un Estado de clase, en el sentido de que pueda servir a una clase 
$u$ otra, porque no se relaciona unilateralmęnte con una clase sino con el sistema social en su conjunto. Lo que equivale a decir que el Estado es un Estado específicamente capitalista, objetiva y estructuralmente. No depende tampoco de una subordianción política o subjetiva del personal del gobierno a intereses capitalistas concretos ni de la presión que éstos puedan ejercer sobre el aparato del Estado como sostenía Miliband, sino que la propia estructura del Estado se adecúa objetivamente al sistema capitalista. Y en la actual fase del capitalismo monopolista, el desarrollo específico de las relaciones de producción, las variaciones experimentadas en la composición orgánica del capital, la caracteristica tendencia a la baja en la tasa media de beneficio y la configuración y el nivel que alcanza la lucha de clases, condicionan de tal forma las exigencias y posibilidades de obtención de la plusvalía, obligadamente relativa, que no puede lograrse, o con unos costes sociales tan altos como de imprevisibles efectos, sin una determinada actuación del Estado. Las demandas hoy del sistema económico al político aumentan en intensidad, precisión y urgencia de tal forma que el Estado debe atenderlas prioritariamente. Lo que quiere decir que el Estado tiene hoy, como primera exigencia, el constituirse de forma tal que las funciones que le demanda el sistema económico (y que desarrolla básicamente en relación con la valorización del capital y las, dialécticamente consecuentes, de armonía o estabilidad social en la concepción de O'Conor) queden garantizadas, mediante la introducción, por otra parte, de los necesarios mecanismos selectivos de que habla Offe(23) y que como elementos correctores excluyan o eliminen las fuerzas o intereses contrarios a los del capital colectivo. Es decir, que este tipo de demandas del sistema económico prima sobre los demás y el Estado debe configurarse, en primer lugar, en forma adecuada para satisfacerlas, subordianando las otras funciones al cumplimiento de éstas.

Por consiguiente, será en esa correspondencia entre una específica estructura organizativa y funcional y el nivel de desarrollo de la actual fase capitalista, donde habrá que buscar la raíz de las transformaciones del Estado y, por tanto, de la producida en los Parlamentos. De acuerdo con ello, el análisis puede hacerse de la siguiente manera:

a) Modificaciones que han implicado o favorecido un cambio en la localización de las decisiones.

La necesidad funcional ha creado su propio aparato institucional. Inicialmente hay que registrar el hecho de que, efectivamente, la realización de las nuevas funciones económico-sociales caracteristicas del, desde otra perspectiva, denominado Welfare State, ha necesitado la creación de un enorme complejo orgánico de Administración que, simultáneamente, ha acumulado, junto a las funciones gestoras, funciones de decisión, convirtiéndose en el lugar privilegiado de la fracción monopolista(24). El hecho es generalmente admitido: la Administración es la que realmente vehicula 
la dominación del capital monopolista; decide en nombre de exigencias "técnicas" que "sólo" ella puede estimar y valorar, en nombre de la "innovación", del "progreso industrial", de los "grandes intereses económicos del país", etc. Es decir, decide y hasta está en condiciones de legitimar esta decisión que encubre una específica dominación (Poulantzas). La Administración pública se convierte en el centro de integración de los intereses conflictivos y en el lugar adecuado para cristalizar el acuerdo y el compromiso (Abendroth). Se llega así-ha podido decirse(25) - a una escisión en la estructura institucional del Estado: de una parte, unas estructuras retóricas ideológimente vertebradas en el acceso masivo de los ciudadanos a la representación parlamentaria y unas estructuras reales extraparlamentarias donde tienen lugar los procesos de decisión tipificados por el ocultamiento y el silencio, es decir, el secreto elevado a razón de Estado como es característico de toda gestión burocrática.

Pero, en definitiva, todo ello supone, como ha señalado Poulantzas, y sin perjuicio de admitir la existencia de múltiples focos de poder en la maraña administrativa-órganos, consejos, comisiones, etc.-con importantes competencias e influencia, un desplazamiento del poder último de decisión al ejecutivo y, en concreto, a su vértice, que es quien realmente domina aunque sea "a través de la Administración". Por lo demás, el hecho, desde el "parlamentarismo racionalizado", no ha dejado de ir adquiriendo consistencia constitucional.

Ahora bien, con todo lo anterior no se hace más que constatar e interpretar una realidad. Debe, por consiguiente, tratarse de buscar una explicación causal. En este orden, los intentos de buscar las causas concretas de esta acumulación de poder en el ejecutivo y de la correspondiente fuga del Parlamento, deben, a mi juicio, tener en cuenta los siguientes hechos interrelacionados entre sí:

1) El Parlamento ha sufrido un cambio que, a un cierto nivel de abstracción, puede expresarse como el paso de lo universal a lo particular. El Parlamento, antes de la irrupción de las masas en los procesos electorales y políticos, tenia una constitución homogénea que le permitía presentarse como "la razón general». El poder legislativo, señala Hégel(26) es el poder de determinar y establecer lo universal y tiene su base en que "la clase universal", consagrada más de cerca al servicio del gobierno, incluye en su determinación de modo inmediato el tener lo universal como fin de su actividad esencial. En el elemento que en el poder legislativo forma la Asamblea de los representantes de los estamentos, la clase privada alcanza significación y eficacia políticas... los diputados representan a la sociedad civil en cuanto tal, es decir, no disuelta atomísticamente en indivíduos que se reunen para un acto singular y temporal... sino que adquieren "conexión política", momento político que, como se sabe, es para Hégel el de la universalidad concreta. Con el sufragio universal y la apari- 
ción de los partidos, lo particular penetra en el Parlamento. La clase universal deja de serlo y su actuación y decisión parlamentaria tiene dificultades para presentarse como la indiscutida "razón general». El lugar tradicional de mediación y encuentro en el que los intereses de las distintas fracciones burguesas podian compatibilizarse, llegar al compromiso y, hasta cierto punto, a la unificación, ya no es válido. Y en la actual fase, la situación se agudiza porque los intereses de la fracción monopolista son tan divergentes de los demás que apenas pueden parlamentarizarse. Las dificultades para imponerse aumentan. $Y$, aún de hacerlo, las propias características del funcionamiento parlamentario (discusión, publicidad, etc.) destruirían su función simbólica, deslegitimarían su propia existencia y hasta el de todo el sistema si se hace patente la inversión de los antiguos términos: el predominio de lo particular sobre lo general.

2) La transformación operada en los Parlamentos que han pasado de ser vehículos de una representación real, directa, unívoca y, por tanto, funcional, a una representación, en determinados supuestos que son además decisivos, inexistente, o, en todo caso, indirecta y por ello mucho menos operativa para los intereses afectados.

A este respecto Bobbio ha señalado que la causa, que él llama político-económica, de la crisis de los Parlamentos, reside, precisamente, en la transformación que se ha producido en la sociedad moderna a partir de la revolución industrial, porque ella es la que ha hecho quebrar las bases de funcionamiento de los parlamentos liberales(27). En éstos, como resultado de una economía menos compleja, los representantes lo eran, directamente, y no a través de persona interpuesta, de los intereses económicos dominantes; es decir, los poderes económicos estaban directamente representados. Poder económico y poder político prácticamente coincidian sin mediaciones.

Pero en la actual fase del desarrollo capitalista, los intereses monopolistas tienen grandes dificultades para encontrar una adecuada representación en el Parlamento. A ello contribuye la dinámica de los procesos electorales que, de manera general, hacen muy difícil la obtención, para este tipo de intereses, de una representación amplia y sólida, pero también otro tipo de factores más concretos..En este sentido señala Birnbaum(28), refiriéndose a la Tercera y Cuarta República Francesa, el fenómeno progresivo de periferización del Parlamento, la dependencia cada vez mayor de los parlamentarios respecto de los intereses locales, que son los que aseguran una reelección, lo que conlleva la pérdida de disciplina de partido y la real ausencia de representación nacional por su falta de sensibilidad para los grandes problemas e intereses. Y como ello va unido-señala Birnbaum-al proceso de concentración monopolista, los grandes poderes del "centro" abandonan el Parlamento y se insertan en la Alta Administración. Al mismo tiempo, en este hecho puede encontrarse el origen 
del desplazamiento que intentan estos intereses para que el conflicto básico empresarios-trabajadores abandone el marco poco propicio del Parlamento y trate de buscar sus vías de integración en lugares extraparlamentarios, lo que a su vez, implicará un nuevo camino de pérdida por el Parlamento de competencias que debieran instrumentarse a través de su función legislativa.

3) Existen, además, nuevas características en la configuración de los Parlamentos actuales que producen la disminución de su influencia socio-política y de su poder real, generando así condiciones favorables para su desplazamiento al poder ejecutivo.

Este hecho se situa en la tendencia general de los sistemas políticos contemporáneos a desvincularse de la base social, de tal forma que el modelo de democracia que se perfila parece cada vez más abstracto y separado de los conflictos de clase(29). Ello se manifiesta de modo específico en los Parlamentos, en la medida en que la representación ha pasado de ser estrictamente orgánica a genérica e indeterminada. $Y$ se produce de manera primordial a través de la transformación operada en los partidos. La hipótesis, de alguna manera, vendría a oponerse a la que habitualmente, aunque desde otros presupuestos, sirve para expresar la crítica partitocrática y, sumariamente, podría formularse así: la crisis de los Parlamentos, por lo que a este aspecto concreto se refiere, se produce por la debilidad que hoy manifiestan los partidos políticos. Debilidad que habria que explicar en función de la característica que de forma general se apuntaba antes: en su progresivo alejamiento de las respectivas bases sociales, que sufren asimismo un proceso de indeterminación. La complejidad y fragmentación de la estructura social de las formaciones del capitalismo desarrollado, el surgimiento de nuevos sectores sociales con su propia problemática, convierte a los partidos, cada vez más, no sólo en partidos interclasistas, sino multisectoriales, lo que unido a las exigencias electorales, hace su representación real, su campo concreto de demandas, su mensaje ideológico y, en definitiva, su programa político, mucho más indefinido. En este orden, sí puede alcanzar alguna vigencia la afirmación de que queriendo "representar" a todos, se termina no representando a nadie. Se da lugar, así, a la constatada cada vez menor identificación con el partido y la característica ruptura del vínculo representantes-represntados que tiende a constituirse como permanente y no sólo como coyuntural tal como fuera advertida y analizada desde Marx y Gramsci. En cualquier caso, el fenómeno forma parte de la peculiaridad del Estado en las sociedades consideradas, que manifiesta una acentuacioń de las características genéricas de crisis situándose en una tendencia de subsisitencia a través de una crisis permanente.

El hecho de la ruptura de aquel vínculo se relaciona igualmente con los fenómenos de apatía, despolitización, etc. y con la aparición, por tanto, 
de circunstancias que favorecen los procesos progresivos de autoritarismo "normal" y aún "excepcional", característicos de nuestro espacio y tiempo políticos.

Con relación al tema que nos ocupa, esos hechos están en la base de la afirmación, hoy compartida, de que los partidos se han convertido de organos de la sociedad en órganos del Estado, de centros de decisiones en correas de transmisión de decisiones del Gobierno, aunque todo ello se disimule por las respectivas burocracias trás pantallas legitimadoras de compromisos y acuerdos realizados en aras de supremos intereses nacionales que deben colocarse por encima de los partidos.

b) Inadecuación funcional de los Parlamentos.

El paso de poder al ejecutivo conlleva en gran parte la supresión de funciones de control y de «indirizzo" políticos. No obstante, permanecería, en principio, la función legislativa como indiscutible función de los Parlamentos y sustentadora del sistema poltico en su conjunto en cuanto mediante ella cobrarian virtualidad los supuestos representativos y democráticos.

Sin embargo, el mantenimiento de su función legislativa en los términos en que se concebia e integraba en la construcción liberal del Estado de Derecho, no es posible ya por un doble tipo de circunstancias:

1) Por exigencias instrumentales.

Según la concepción clásica, en cuanto el Parlamento representaba a la totalidad nacional, la ley no sólo expresaba "la voluntad general», sino que su propio contenido era "la racionalidad social general". Por eso, señalaba Schmitt, que la ley no sólo era "voluntas" sino "ratio". Racionalidad que por otra parte, como ha indicado Habermas, respondia a las exigencias de la racionalidad propia del capitalismo liberal(30). Los caracteres de la ley, general y abstracta, no sólo eran reales sino que se acomodoban también a las exigencias de un Estado caracterizado por un papel fundamentalmente negativo y cuyas actuaciones positivas se mantenían en los límites de las identidades de los ciudadanos y no de sus diferencias, como en otro lugar se señalaba.

Un instrumento así deja de tener sentido cuando el Estado pasa de definirse negativa a positivamente, de la actuación mínima a la permanente, de moverse en el terreno de lo común al de lo diferencial, y, sobre todo, cuando las demandas del sistema socioecónomico exigen actuaciones coyunturales rápidas y con contenidos singulares adecuados a fines e intereses sectoriales muy concretos. En base a todo ello se ha tratado de justificar el conocido conjunto de mecanismos a través de los cuales se ha producido el importante desplazamiento real de la función legislativa al ejecutivo: traslado directo de competencias como en el caso de la Constitución 
francesa, delegación de las mismas, práctico monopolio por el gobierno de la iniciativa legislativa(31), necesidad de una actuación del ejecutivo para la puesta en marcha de las leyes aprobadas por el Parlamento, etc.

Pese ello, la conservación, siquiera sea formal o disminuida, de la función ha producido la inflación legislativa característica de los Parlamentos modernos que ha puesto a prueba-según sus críticos-una manifiesta insuficiencia de los mismos, sin que se cuestiones la razón y la necesidad de aquélla.

2) Por razones estrictamente políticas.

La actuación del Estado contemporáneo, de acuerdo con lo que se lleva dicho y como se ha señalado repetidamente, es necesariamente, cada vez más, sesgada y parcial, lo que obliga a reforzar los mecanismos ideológico-políticos de legitimación, tratándose, entre otras formas, de incluir en el área estatal al mayor número de sectores y grupos, de extender a nuevos espacios la organización de base representativa en un intento de institucionalizar e integrar la dinámica social. El intento resulta favorecido porque como, en último término, las necesidades objetivas son muy concretas, como las demandas del sistema económico al político son cada vez más específicas, las respuestas también deben serlo y, por consiguiente, los programas y alternativas de los partidos que traten de permanecer en el interior del sistema no pueden ser muy distintos, con lo que se produce esa característica de las democracias contemporáneas de ser, no ya sujetivamente por supuestas voluntades de compromiso de las direcciones de los partidos sino estructuralmente, consensuales(32), en cuanto sus respectivos proyectos políticos deben estar, objetivamente muy próximos.

Con todo ello, el sistema político, en cuanto se considera cada vez más legitimado democráticamente, se encuentra también cada vez más legitimado para "defenderse". Será, incluso, un presupuesto aceptado por la izquierda. Cerroni afirmará: "el radicalismo ignora completamente el hecho de que hoy la principal garantía a denfender es la existencia misma del Estado democrático»(33).

Surgen, sin embargo, las contradicciones. De una parte, la "estatalización de la sociedad", como se ha denominado el fenómeno antes descrito, unida a la intervención del Estado en ámbitos cada vez más amplios, produce no sólo una "politización» de prácticamente todos los conflictos, sino un enfrentamiento de un número cada vez mayor de luchas reivindicativas-como señalara Poulantzas-con el Estado que se encuentra y con el que se choca en todas partes. De otra, como precisamente el abanico de posibilidades desde dentro del sistema es cada vez menor, según veiamos, el intento de estatalización social es cada vez más contradictorio, quedando crecientemente-y en la medida en que el desarrollo 
socio-económico produce nuevos sectores reivindicativos-grupos, demandas y planteamientos fuera de las posibilidades del sistema. Pretendiendo y aparentando incluir cada vez más, de hecho cada vez cabe menos. Y la respuesta será "defender el Estado democrático". En base a aquella legitimasción se acentúan los mecanismos de represión y control social. Es el conocido fenómeno, en el que no vamos a insistir, de suscitar la sensación de crisis y peligro generalizado, para buscar en el ciudadano, al que se trata de implicar mediante su colaboración en la represión, la preferencia de la seguridad a la libertad. Los mecanismos jurídicos utilizados muestran con frecuencia que el efecto de todo ello es la ruptura del principio de legalidad. La creciente normativa de excepción vigente hoy en Europa lo confirma sobradamente. Y, en definitiva, la crisis de los Parlamentos se vincula a la crisis general del Destado de Derecho.

Pese a todo lo anterior, los Parlamentos subsisten. Pese a la analizada crisis política y crisis de eficiencia, lo cierto es que no ha aparecido todavía ninguna propuesta que, manteniéndose dentro de los supuestos de las democracias occidentales, abogue por su supresión. Y probablemente no por las razones por las que Max Weber señalaba: "la eliminación verdaderamente completa de los parlamentos-decia-no la ha postulado seriamente ningún demócrata... en cuanto instancia para la consecución del carácter público de la Administración, para la fijación del Presupuesto y para la discusión y aprobación de las leyes, funciones en las que son efectivamente insustituibles en toda democracia, es probable que se los quiera dejar subsisitir en todas partes(34)". Si juzgáramos por esta previsión de Max Weber la capacidad de predicción de las ciencias sociales, no era ciertamente para sentirse optimistas. Porque justamente las funciones que señala como atribuibles de manera insustituible a los Parlamentos, son las que precisamente han dejado en gran parte de pertenerle realmente. Si el Parlamento no cumpliera otras funciones, siguiendo el razonamiento de Max Weber, no habría mayores inconvenientes en hacerlo desaparecer. Y si no ha sido así, es porque cumple otras más favorables y necesarias. En este sentido, la función básica que desarrollan los Parlamentos se relaciona con la contradicción que destacara inicialmente Habermas entre la ideología del capitalismo avanzado y la lógica de la acumulación, entre las necesarias precondiciones del sistema y el proceso de reproducción capitalista que genera un inevitable sistema autoritario de decisiones como señala Offe, entre las funciones políticas simbólicas y las funciones capitalistas reales acentuada por las crisis económica recurrente y el nivel de la lucha de clases como lo expresa Ferrajoli, en definitiva, con la crisis de legitimaçión a la que antes aludíamos.

En este sentido afirma Perry Anderson(35) que "la forma general del Estado representativo es, en sí misma, el principal cerrojo ideológico del capitalismo occidental, cuya existencia despoja a la clase obrera de la idea 
del socialismo como un tipo diferente de Estado y, con posterioridad, los medios de comunicación y otros mecanismos de control cultural afianzan este efecto ideológico central». Porque-añade-si el Estado representa a la totalidad de la población abstraída de su distribución en clases, lo político separado de lo económico, el Parlamento, elegido como la expresión soberana de la voluntad popular, refleja ante las masas la unidad ficticia de la nación como si fuera su propio autogobierno. La existencia del Parlamento es el marco formal de todos los demás mensajes ideológicos de la clase dominante. Proporciona el código en el que se transmiten todos los mensajes. Y ello tiene una importancia decisiva, ya que-señala en otro lugar(36) - la base de que se obtenga el consenso de las masas en las modernas formaciones sociales capitalistas, está en la creencia en la igualdad democrática de todos los ciudadanos en el Gobierno de la nación; en otras palabras, en la no creencia en la existencia de ninguna clase dirigente.

En la misma línea-afirma Hodgson-que "el reconocimiento de la igualdad democrática se convierte en una fuerza social real; por eso, la apariencia deja en cierto modo de serlo y se convierte en realidad. Y, obviamente, es a través del Parlamento como este efecto se consigue porque el Parlamento es de alguna forma la prueba de que esto es así.

Posiblemente tienen fundamento real las afirmaciones ariteriores en cuanto se refieren a un "efecto general" del Parlamento sobre el sistema político en su conjunto; sin embargo, me parece, que deben hacerse algunas correcciones. De una parte, enfatizan demasiado la creencia que suscita el Parlamento en los ciudadanos acerca de la "representación nacional", la "igualdad democrática", etc.-lo que impediría, prácticamente, hablar de crisis de legitimación-sin tener en cuenta que, pese a todo, la penetración en el Parlamento de representantes de las clases dominadas así como el sentido cada vez más claro de las decisiones estatales, ha producido una erosión notable de toda la ideología liberal sobre el Parlamento. De otra, no se valoran suficientemente otras vías institucionales de legitimación, como son las que están en condiciones de generar el Ejecutivo y la Administración. Y, finalmente, porque no tienen en cuenta que junto a aquel efecto general, el Parlamento cumple otras funciones específicas de legitimación, entre las que destacan-como ha señalado Agnoli, quien a mi juicio cae en el extremo contrario al considerar la quiebra de la función general simbólica(37) - las siguientes: 1) En primer lugar, la de constitucionalizar las decisiones, hacerlas aparecer como ajustadas a la constitución, beneficiándolas del apoyo constitucional. 2) En segundo lugar, suscitar la imagen de un control de las oligarquias políticas y sociales al hacerlas aparecer en distintos momentos ante el Parlamento, siquiera sea en cuestiones no decisivas o aunque no se llegue a resultado alguno.3) En tercer lugar, al aparecer como portador de deseos, crítica, problemática, 
reivindicaciones de las bases sociales, no sólo se ofrece, al menos-dice Agnoli-para el público menos informado pero que justamente es el que más interesa que entre en el juego parlamentario, la prueba empírica de la democracia, sino, y creo que fundamentalmente, la parlamentarización y reconducción del conflicto y hasta la generación de la conciencia de que el único camino de la lucha de masas es el parlamentario, influyendo-dice Hodgson-tanto en los participantes como en sus direcciones organizativas.

En definitiva, la historia no se equivoca. $Y$ aquí se pone una vez más de manifiesto. El sistema tiene el Parlamento que necesita. $Y$, desde esta perspectiva, sería cuestionable hablar de crisis de los Parlamentos que, en muchos casos y en cuanto queda reducido su tratamiento a problemas técnicos o funcionales de partidos, grupos parlamentarios, procedimientos, etc., no hace sino encubrir ideológicamente las causas de las transformaciones operadas.

Planteadas así las cosas, las preguntas siguientes podrian ser éstas: ¿Qué hacer con los Parlamentos?, ¿Cuál es el tratamiento de su presunta patologia?. En realidad, si los planteamientos anteriores tienen algún sentido, la respuesta consecuente seria: Si los Parlamentos actuales, su situación y funcionamiento se relacionan con las causas profundas que han dado lugar a un tipo concreto de Estado, sólo la modificación de estos factores reales puede producir su transformación. Norberto Bobbio asi lo afirma: "no se trata de un problema-dice refiriéndose a la crisis de los Parlamentos-que afecte a una estructura formal dada y que sea resoluble con medios técnicos, sino de la transformación profunda de la sociedad en la que el Parlamento desarrolla su trabajon.

Por eso, cuando se opera desde los supuestos de los que aquí se parte y en los que me situo, más que la preocupación por la mejora "técnica" de los Parlamentos que potencien su "eficiencia», hay antes que resolver otra cuestión: ¿Para qué los Parlamentos?. Porque sólo una vez determinadas con claridad la finalidad a la que deban servir podrán establecerse los adecuados criterios que hagan de los Parlamentos instrumentos funcionales. Desde este punto de vista, la perspectiva en que aquí se considera el problema es la siguiente: ¿Pueden los Parlamentos, a pesar de su situación y configuración actuales, vincularse a un proceso de transformación general de lą sociedad?, ¿Queda en los Parlamentos alguna virtualidad que pueda potenciarse para coadyuvar en un proceso de democratización real?.

Es el tema que anunciábamos antes como un segundo aspecto a considerar en este trabajo. 
Realmente, el análisis de la función de los Parlamentos en un proceso de transformación social, se encuadra en la problemática general de la transición al socialismo. Su desarrollo excede, pues, de la temática aquí considerada aunque sea necesario tener en cuenta algunos aspectos.

En principo, y muy sintéticamente, cabe señalar que las vías históricamente ensayadas con cierto nivel de generalidad para conceguir la transformación socialista, han sido la vía insurreccional abierta en Octubre del 17 en Rusia y la via pacifica desarrollada fundamentalmente por la socialdemocracia. El triunfo de la primera produjo un cambio decisivo en la historia universal que, paradójicamente, el fracaso y persistencia de la segunda han contribuido en buena parte a detener (junto a otros muchos factores ciertamente).

No obstante y como han señalado entre otros P. Anderson(38) y $L$. Ferrajoli(39), inicialmente, las diferencias entre los presupuestos de una y otra, entre leninismo y reformismo-en los aspectos concretos a que aquí nos referimos son más tácticas que estratégicas, en cuanto ambas se plantean como objetivo prioritario la conquista del Estado; es decir-señala Ferrajoli-en realidad ambas comparten la perspectiva idealista del predominio de lo político, si bien con la diferencia de que en la Rusia del 17 el Estado era "el poder" mientras que en las sociedades actuales no es exactamente asi. Igualmente, pese a las diferencias de todo orden entre una y otra, presentan-indica Poulantzas-una connivencia de fondo: una, a través de la degeneración estalinista, $y$, otra, a través de la degeneración del sistema representativo, ambas han conducido a la hipertrofia estatal autoritaria.

Finalmente, hay que constatar que no se ha producido el tránsito al socialismo en ninguna sociedad de capitalismo avanzado. De ello resulta que, si bien el modelo de Octubre no es aplicable, el comprobado resultado en la aplicación de las tésis socialdemócratas patentizan hasta la evidencia los efectos del reformismo. Habría que recordar a este respecto que si Berstein, a partir de la autocrítica de Engels sobre los errores cometidos en la interpretación de las revoluciones del 48 , señaló que se trataba en realidad de la quiebra de los presupuestos teóricos del marxismo (el proceso de acumulación de capital nó producía la concentración prevista, las crisis eran cada vez menos frecuentes y menos agudas, la polarización de clases no se producia, el poder pasaba a instituciones democráticas perdiéndolo la burguesía) por lo que propone frente a la revolución la reforma del Estado en base a que el Estado representativo con su gobierno parlamentario tiene capacidad para eliminar los conflictos de clase, se podría hoy, aplicando un razonamiento semejante, decir que estas previsiones se han incumplido espectacularmente y no por meros errores de apreciación sino 
por la quiebra de los supuestos teóricos reformistas. Es, quizás, la hora de hacer la revisión al revisionismo.

En cualquier caso, lo cierto es que todavía hoy los planteamientos en torno àl paso al socialismo y al papel del Parlamento en él, se basan y se situan más en la tradición del pensamiento revolucionario que en la del socialdemócrata.

La importancia y función de los Parlamentos en orden a una transformación social, tiene, en lo que puede considerarse el pensamiento revolucionario clásico, una relativa unidad de perspectiva.

Marx, pese a las críticas al Parlamento burgués y a las diferencias que señala con la comuna de Paris, no deja de señalar también la distancia que separa el predominio del ejecutivo (que uexpresa la heteronomía de la Nación») respecto al del legislativo (que "expresa su autonomía»(40), así como la importancia que en la crítica a la Filosofía del Derecho de Hegel concede, igualmente, a la respectiva situación de predominio de uno u otro, vinculando el segundo a la "gran revolución" y el primero a la "pequeña revolución»(41).

Con Engels se plantea ya con más claridad la valoración de lạs plataformas legales y parlamentarias de la República democrática. "La ironía de la historia-dirá-lo vuelve todo del revés. Nosotros los revolucionarios, los subversivos, prosperamos más con los medios legales que con los ilegales y la subversión. Los partidos del orden, como ellos se autodenominan, van a la ruina con el ordenamiento legal que ellos mismos han creado. Exclaman desesperados con Odilón Barrot, la legalité nos tue, mientras nosotros con esa legalidad echamos músculos vigorosos, mejillas sonrosadas y prosperamos que es un placer". Y en cuanto observa que en las sociedades modernas la revolución no es un acto concreto ni resultado de la actividad de unas minorias sino fruto de una larga y paciente labor, da mayor relevancia a la "acción parlamentariaw(42). Y, precisamente por ello, señalará en otra parte que la República democrática es la única forma de Estado bajo la cual puede darse la batalla entre el proletariado y la burguesía(43).

Lenin, basará gran parte de las críticas a los "izquierdistas" en la negativa de éstos a participar en los Parlamentos burgueses despreciando la utilidad que pueden prestar como "foro" y lugar para la "expresión de la ideologíaw(44), destacando, asimismo, las ventajas de la República democrática para el proceso revolucionario(45).

La postura de Lenin pasaría a ser la "oficial" de la Internacional (segundo congreso) que, en la formulación de Bujarín, redactor de las tesis correspondientes, afirmaria que, "si en la época precedente el Parlamento cumplió una función históricamente progresiva, en la fase del imperialismo no puede servir como centro de lucha porque el centro de gravedad se 
ha desplazado del Parlamento; los Parlamentos burgueses, se dice, no pueden ser ganados permanentemente como tales del mismo modo que el proletariado no puede ganar el Estado burgués... En la lucha de masas, el partido dirigente del proletariado debe lograr, como norma, todas las posiciones legales, usándolas como centros auxiliares e incorporándolas a su plan principal de campaña... el partido comunista no participa en esta institución para funcionar en ella como parte orgánica sino para actuar dentro de ella, para ayudar a destruir la máquina estatal y el Parlamento mismo".

En el Programa de Transición elaborado por Trotsky para la IV Internacional, aunque las "reivindicaciones democráticas" adquieren mayor importancia, en el tema concreto de la valoración de los Parlamentos no se introducen aportaciones significativas.

Asi pues, en esta etapa, el Parlamento no tiene sino una consideración subalterna en cuanto puede servir de foro y propaganda, de elemento auxiliar de la lucha de masas que se vertebra de manera principal no por la vía parlamentaria sino por la soviética o consejista.

Con posterioridad y en los momentos actuales, toda la discusión en torno al tema girará en base a la dialéctica entre ambas vias, de forma que hoy las tendencias básicas pueden establecerse de acuerdo con las posturas que se mantengan acerca de esas alternativas. De acuerdo con ello, cabe asi distinguir: 1) Se mantiene una posición de extrema desconfianza sobre las posibilidades de los Parlamentos. Agnoli indicará que todos los intentos de hacer avanzar la democracia tratando de reanimar las instituciones répresentativas, sólo pueden tener algún sentido en sociedades desintegradas. Toda reforma parlamentaria que se intente en Estados que manifiestan una orientación involutiva-que es para Agnoli una exigencia de la dominación en las formaciones de capitalismo desarrollado-no sirve para ampliar la participación de las masas en el poder, sino para contenerlas más fácilmente. Ninguna opinión pública políticamente articulada que sea antagonista, ni a veces la meramente crítica, encontrará en el Parlamento instrumento alguno para hacerse práctica. Porque el Parlamento no es representante del pueblo sino del poder y, por eso, uparlamentarizarse" la oposición, es renunciar a toda política transformadora, es convertirse en un agente más del statu quo, entrar en el "consenso»(46).

Así pues, se rechaza el Parlamento no sólo porque no se le reconoce virtualidad política transformadora aiguna sino porque, incluso, se le considera extremadamente peligroso por sus efectos sobre la dosmeticación de la lucha y el conflicto.

2) Se abandona y hasta se combate la vía consejista.

La mayoría de los partidos comunistas occidentales así lo sostienen teórica y prácticamente. Los argumentos pueden sintetizarse en los que 
expusiera Ingrao en su polémica con Magri:

- La democracia consejista es históricamente improponible en una sociedad compleja y está superada por toda la estrategia elaborada con posterioridad en base a las propuestas de Togliatti, Gramsci, etc.

- La vía consejista es inaplicable hoy porque toda dinámica revolucionaria pasa por una política de alianzas; aquélla, por el contrario, impide toda alianza de clase y plantea esquemáticamente la lucha de clase contra clase, lo que es garantía de inoperancia y fracaso.

- La vía consejista es rechazable porque propone una conquista del poder en el lugar de la producción, con un abandono prácticamente total del partido y los sindicatos.

La práctica de los partidos comunistas muestra, efectivamente, no sólo un abandono de los consejos sino que vienen desarrollando un casi absoluto "reduccionismo institucional» con una pérdida clara de interés por otras formas organizativas y de lucha.

3) Finalmente, la postura que trata hoy de abrirse camino y que parece ofrecer una mayor fundamentación teórica y unas mayores posibilidades prácticas es la que intenta una articulación entre ambas vías: la parlamentaria y la consejística.

Hay en este intento una inicial revalorización de la vía consejista, bien entendido que de lo que se trata es de una actualización, tanto en su comprensión como en su aplicación, que la haga capaz de desplegar sus virtualidades en una sociedad como la actual. Los fundamentos en que se basa son, a mi juicio, los siguientes:

- Por una parte, en que el Estado no es algo monolítico sino que está atravesado de contradicciones y que estas contradicciones se producen y agudizan, precisamente, mediante la lucha de masas. El proceso de lucha en la correlación de fuerzas dentro del Estado tiene que acompañarse del correspondiente proceso fuera del Estado. La penetración de este proceso "externo" en el interior del Estado y en sus aparatos más herméticos es perfectamente posible como lo demuestran los comportamientos contemporáneos de algunos ejércitos europeos.

- Por otra, se basa en la importancia que hay que seguir dando hoy al conflicto social básico, excesivamente relativizado por toda una teorización que privilegia las complejidades y características de la actual estratificación social así como la configuración del "nuevo sujeto revolucionarion. En relación con ello se afirma, sin embargo, que el conflicto básico sigue siendo esencialmente el mismo: la contradicción entre la pretensión de dominio privado, individual, privilegiado, de la propiedad, poder de disposición y saber y los contenidos de una sociedad moderna basada en la producción colectiva. Lo que ocurre es que las formas de manifestarse el 
conflicto han multiplicado, ramificado, ocultado y disimulado el anterior antagonismo, más simple y fácil de percibir, entre explotadores y explotados(47). No hay que olvidar, además, que con frecuencia las nuevas contradicciones y conflictos (paro, destrucción del medio ambiente, opresión de la mujer, etc.) se concentran preferentemente en las clases trabajadoras que las sufren todas. Todo ello no implica desconocer que, ciertamente, los nuevos desarrollos sociales no introduzcan factores disfuncionales en las clases trabajadoras, como la división del movimiento obrero o el desarrollo del corporativismo, etc.(48).

A partir de estos supuestos se defiende la vía consejista actualizada con dos tipos de argumentos. Por un lado, en cuanto constituye-se afirma-el instrumento revolucionario adecuado tanto para que los trabajadores puedan adquirir conciencia por sí mismos (de acuerdo con las tesis de Rosa Luxemburgo y en contra de la inicial postura de Lenin, después rectificada) como porque en la práctica, a través de este tipo de organizaciones o movimientos, puede conseguirse la real unidad de acción que supere las falsas alianzas intentadas ante la complejidad social "del capitalismo maduro pero que la realidad ha demostrado que sólo conducen a convergencias de carácter corporativos(49). Por otro, porque pueden ser el medio adecuado para la ruptura a que en algún momento hay que llegar y que nadie discute y el nivel institucional adecuado para etapas posteriores, en las que, como se sabe, este nivel institucional pasará a ser el dominante en cuanto es el que anula las relaciones de producción capitalista(50).

Y junto a esta revalorización de este tipo de órganos, eludiendo el rechazo de que han sido objeto por el revisionismo, hay también una revalorización de la institución parlamentaria, eludiendo el rechazo de que ha sido objeto por el pensamiento revolucionario más tradicional. Esta revalorización se basa en dos supuestos:

-Una reconsideración de la importancia de lo político y, en concreto, de las instituciones estatales y de su función en las sociedades contemporáneas en base al nuevo papel que desempeñan respecto del sistema económico.

- Una revalorización de los supuestos del Estado de Derecho, de la legalidad y de las libertades tanto en sí mismos como por la condición de prerrequisitos(51).

La postura de Lenin pasaria a ser la "oficial" de la Internacional (segundo congreso) que, en la formulación de Bujarin, redactor de las tesis correspondientes, afirmaria que, "si en la época precedente el Parlamento cumplió una función históricamente progresiva, en la fase del imperialismo no puede servir como centro de lucha porque el centro de gravedad se ha desplazado del Parlamento; los Parlamentos burgueses, se dice, no 
pueden ser ganados permanentemente como tales del mismo modo que el proletariado no puede ganar el Estado burgués... En la lucha de masas, el partido dirigente del proletariado debe lograr, como norma, todas las posiciones legales, usándolas como centros auxiliares e incorporándolas a su plan principal de campaña... el partido comunista no participa en esta institución para funcionar en ella como parte orgánica sino para actuar dentro de ella, para ayudar a destruir la máquina estatal y el Parlamento mismo».

En el Programa de Transición elaborado por Trotsky para la IV Internacional, aunque las "reivindicaciones democráticas" adquieren mayor importancia, en el tema concreto de la valoración de los Parlamentos no se introducen aportaciones significativas.

Asi pues, en esta etapa, el Parlamento no tiene sino una consideración subalterna en cuanto puede servir de foro y propaganda, de elemento auxiliar de la lucha de masas que se vertebra de manera principal no por la vía parlamentaria sino por la soviética o consejista.

Con posterioridad y en los momentos actuales, toda la discusión en torno al tema girará en base a la dialéctica entre ambas vịas, de forma que hoy las tendencias básicas pueden establecerse de acuerdo con las posturas que se mantengan acerca de esas alternativas. De acuerdo con ello, cabe asi distinguir: 1) Se mantiene una posición de extrema desconfianza sobre las posibilidades de los Parlamentos. Agnoli indicará que todos los intentos de hacer avanzar la democracia tratando de reanimar las instituciones representativas, sólo pueden tener algún sentido en sociedades desintegradas. Toda reforma parlamentaria que se intente en Estados que manifiestan una orientación involutiva-que es para Agnoli una exigencia de la dominación en las formaciones de capitalismo desarrollado-no sirve para ampliar la participación de las masas en el poder, sino para contenerlas más fácilmente. Ninguna opinión pública políticamente articulada que sea antagonista, ni a veces la meramente crítica, encontrará en el Parlamento instrumento alguno para hacerse práctica. Porque el Parlamento no es representante del pueblo sino del poder y, por eso, "parlamentarizarsen la oposición, es renunciar a toda política transformadora, es convertirse en un agente más del statu quo, entrar en el "consenso»(46).

Así pues, se rechaza el Parlamento no sólo porque no se le reconoce virtualidad política transformadora alguna sino porque, incluso, se le considera extremadamente peligroso por sus efectos sobre la dosmeticación de la lucha y el conflicto.

2) Se abandona y hasta se combate la vía consejista.

La mayoría de los partidos comunistas occidentales asi lo sostienen teorica y prácticamente. Los argumentos pueden sintetizarse en los que expusiera Ingrao en su polémica con Magri: 
- La democracia consejista es historicamente improponible en una sociedad compleja y está superada por toda la estrategia elaborada con posterioridad en base a las propuestas de Togliatti, Gramsci, etc.

- La vía consejista es inaplicable hoy porque toda dinámica revolucionaria pasa por una política de alianzas; aquélla, por el contrario, impide toda alianza de clase y plantea esquemáticamente la lucha de clase contra clase, lo que es garantía de inoperancia y fracaso.

- La vía consejista es rechazable porque propone una conquista del poder en el lugar de la producción, con un abandono prácticamente total del partido y los sindicatos.

La práctica de los partidos comunistas muestra, efectivamente, no sólo un abandono de los consejos sino que vienen desarrollando un casi absoluto "reduccionismo institucional» con una pérdida clara de interés por otras formas organizativas y de lucha.

3) Finalmente, la postura que trata hoy de abrirse camino y que parece ofrecer una mayor fundamentación teórica y unas mayores posibilidades prácticas es la que intenta una articulación entre ambas vías: la parlamentaria y la consejística.

Hay en este intento una inicial revalorización de la vía consejista, bien entendido que de lo que se trata es de una actualización, tanto en su comprensión como en su aplicación, que la haga capaz de desplegar sus virtualidades en una sociedad como la actual. Los fundamentos en que se basa son, a mi juicio, los siguientes:

- Por una parte, en que el Estado no es algo monolítico sino que está atravesado de contradicciones y que estas contradicciones se producen y agudizan, precisamente, mediante la lucha de masas. El proceso de lucha en la correlación de fuerzas dentro del Estado tiene que acompañarse del correspondiente proceso fuera del Estado. La penetración de este proceso "externo" en el interior del Estado y en sus aparatos más herméticos es perfectamente posible como lo demuestran los comportamientos contemporáneos de algunos ejércitos europeos.

- Por otra, se basa en la importancia que hay que seguir dando hoy al conflicto social básico, excesivamente relativizado por toda una teorización que privilegia las complejidades y características de la actual estratificación social así como la configuración del unuevo sujeto revolucionario». En relación con elio se afirma, sin embargo, que el conflicto básico sigue siendo esencialmente el mismo: la contradicción entre la pretensión de dominio privado, individual, privilegiado, de la propiedad, poder de disposición y saber y los contenidos de una sociedad moderna basada en la producción colectiva. Lo que ocurre es que las formas de manifestarse el conflicto han multiplicado, ramificado, ocultado y disimulado el anterior 
antagonismo; más simple y fácil de percibir, entre explotadores y explotados(47). No hay que olvidar, además, que con frecuencia las nuevas contradicciones y conflictos (paro, destrucción del medio ambiente, opresión de la mujer, etc.) se concentran preferentemente en las clases trabajadoras que las sufren todas. Todo ello no implica desconocer que, ciertamente, los nuevos desarrollos sociales no introduzcan factores disfuncionales en las clases trabajadoras, como la división del movimiento obrero o el désarrollo del corporativismo, etc.(48).

A partir de estos supuestos se defiende la vía consejista actualizada con dos tipos de argumentos. Por un lado, en cuanto constituye-se afirma-el instrumento revolucionario adecuado tanto para que los trabajadores puedan adquirir conciencia por sí mismos (de acuerdo con las tesis de Rosa Luxemburgo y en contra de la inicial postura de Lenin, después rectificada) como porque en la práctica, a través de este tipo de organizaciones o movimientos, puede conseguirse la real unidad de acción que supere las falsas alianzas intentadas ante la complejidad social "del capitalismo maduro pero que la realidad ha demostrado que sólo conducen a convergencias de carácter corporativow(49). Por otro, porque pueden ser el medio adecuado para la ruptura a que en algún momento hay que llegar y que nadie discute y el nivel institucional adecuado para etapas posteriores, en las que, como se sabe, este nivel institucional pasará a ser el dominante en cuanto es el que anula las relaciones de producción capitalista(50).

Y junto a esta revalorización de este tipo de órganos, eludiendo el rechazo de que han sido objeto por el revisionismo, hay también una revalorización de la institución parlamentaria, eludiendo el rechazo de que ha sido objeto por el pensamiento revolucionario más tradicional: Esta revalorización se basa en dos supuestos:

- Una reconsideración de la importancia de lo político y, en concreto, de las instituciones estatales y de su función en las sociedades contemporáneas en base al nuevo papel que desempeñan respecto del sistema económico.

- Una revalorización de los supuestos del Estado de Derecho, de la legalidad y de las libertades tanto en sí mismos como por la condición de prerrequisitos(51).

Una revalorización más matizada del sistema representativo y de la institución parlamentaria que se entiende que posèe estructural y funcionalmente, una potencialidad ambivalente: si bien desempeña el negativo papel que antes se ha contemplado, también puede constituirse en el vehículo fundamental de penetración de las contradicciones en el Estado y en el de irradiación de cada una de ellas a la sociedad, teniendo en cuenta, además, su mayor permeabilidad a las clases dominadas y en general a los intereses que carecen de una mediación adecuada. 
Por ello, Hodgson(52), al plantearse el tema de las dos vias y optar por la articulación entre ambas, concede un inicial protagonismo al Parlamento al señalar que por él tiene que empezar el avance, por la conquista de la mayoria, y, desde ahí, impulsar y legitimar las transformaciones reales que tengan lugar fuera del Parlamento: movilizar las organizaciones populares de base, apoyarlas y fortalecerlas legalmente, legalizar las transformaciones que se vayan produciendo y abrir nuevas vías a través de una legislación adecuada. Una mayoria parlamentaria, a sensu contrario, deslegitima y hace cada vez más difícil una reacción por la fuerza.

Es decir, las capacidades y funciones de integración y legitimación del Parlamento que vimos con anterioridad, muestran su, antes señalada, ambivalencia, en cuanto puede actuar: 1) Como elemento legitimador de las organizaciones y actuaciones extraparlamentarias y garantía de la consolidación de las conquistas que se vayan obteniendo, lo que puede permitir la instalación en el Estado de lo que Poulantzas llama centros de resistencia, que favorezcan un proceso de sucesivas rupturas con vistas a un cambio gradual en la correlación de fuerzas. Este aspecto del Parlamento como "defensor» está en la más pura línea de la teoria de la revolución, porque efectivamente, desde Trotsky se sostiene que un proceso revolucionario avanza mejor en la medida en que la revolución aparezca como defensora de logros ya conseguidos.

2) Como lugar de agregación de intereses y demandas. La capacidad del Parlamento para actuar como representante de intereses generales le permite vincular y "englobar" a diferentes fracciones cuya alianza es necesaria y no tienen cabida en los consejos u organizaciones salidos de los centros de trabajo así como "generalizar" intereses sectoriales.

3) El Parlamento puede actuar, además, como impulsor y hegemonizador de sectores politicamente atrasados e incluso de fracciones «basculantes" (como grupos de la pequeña burguesia) que potencialmente pueden, incluso, convertirse en adversarios.

El problema que se plantea es el de la compatibilidad entre ambas vías. A este respecto se ha señalado(53), cómo inicialmente los consejos surgen para presionar sobre lo existente y conseguir moderadas reformas y sólo con posterioridad terminan enfrentándose al Estado por las caracteristicas autocráticas del régimen del Zar; pero si aún en ese régimen pasan por una etapa de convivencia, hay que pensar que en un régimen democrático como el que debe suponerse que existe para que puedan plantearse las hipótesis que aquí se manejan, las relaciones serán más complejas, pacíficas y de apoyo mutuo, por lo que no tendrá sentido presentarlos ni como alternativos ni como lo que ha funcionado como mito en la tradición revolucionaria: el doble poder.

En todo caso, el problema de la compatibilidad y articulación se 
complica indudablemente por algo que se apuntaba antes, que es hoy objeto de discusión en la izquierda y que indicaremos brevemente. Si bien es cierto. que la complejidad que adquiere hoy la estratificacion social introduce elementos de ocultamiento del conflicto básico, también ha creado (además de nuevas fracturas entre la clase dominante y en la estructura de sus alianzas clásicas) nuevas disfuncionalidades y desigualdades sociales que abren nuevos frentes de lucha: división de los trabajadores con demandas específicas, movimientos de liberación femenina al hacerse más patente su opresión, movimientos urbanos que han hecho estallar la concentración de la población, movimiento ecologista surgido del característico crecimiento desordenado que produce la destrucción del medio, la contradicción entre el nivel educativo alcanzado y las exigencias de la taylorización, el paro, etc.(54). Ello genera-señala Améndola-un serio problema: el necesario mantenimiento de las respectivas autonomías de los movimientos, exigidas por las correspondientes tácticas dirigidas a la consecución de los diferentes objetivos, asi como de la democracia directa de muchas de estas organizaciones, y su relación con el que es el centro de la democracia delegada o representativa: el Parlamento. En la coordinación entre ambos niveles, sindicatos y partidos tienen un nuevo papel, lo que a su vez les crea nuevas necesidades de ajuste y democratización tanto por las exigencias extra como intraparlamentarias de los nuevos planteamientos.

Como muestra de que la articulación entre ambas vías es posible, Hodgson aporta dos ejemplos significativos ocurridos en Gran Bretaña: uno referido al surgimiento del movimiento libertario de las comunidades de trabajo y que a partir de 1.968 obtuvieron el apoyo parlamentario que consiguió su consolidación, legalizándolos; otro, el Acuerdo de planificación (sindicatos-partido Laborista) que contiene una coordinación entre el control obrero a nivel de empresa y una economía planificada y que, aunque de forma más diluída, se incluy.ó en el proyecto industrial del gobierno Laborista.

Me parece, no obstante, que más que discutir sobre las posibilidades teóricas de la articulación hay que tener en cuenta que su necesidad ha de imponerla por caminos a priori impensables en la medida en que los procesos avancen y se radicalicen. Acaso el ejemplo más claro de esta necesidad sea el que ha dado el IRA que, aun en las peores condiciones parlamentarias, ha terminado aceptando incluir esta vía en su estrategia global(55).

Ante lo expuesto, podría concluirse de la siguiente manera:

1) La concepción de la crisis de los Parlamentos es, en gran medida, producto de una orientación positivista que parte de un modelo ideal de Parlamento que nunca existio, aunque trata de hipostasiarlo en el modelo liberal, y que, con sus intentos de explicación simples y fragmentarios, 
contribuye a ocultar la realidad de la transformación histórica de los Parlamentos determinada por y funcional a la fase de desarrollo socioeconómico en los paises de capitalismo dominante.

2) Hay que aceptar, pese a lo anterior, que la ambivalencia de la institución parlamentaria ofrece posibilidades para un proceso de democratización real, si bien este proceso no puede realizarse a través de un exclusivo reduccionismo parlamentario, con lo que se plantea el problema de articular la vía perlamentaria y la extraparlamentaria que debe resolverse desarroliando formas de coordinación que tiendan a la integración y globalización de los distintos movimientos autónomos.

3) Es en relación con estas posibilidades que ofrece el Parlamento como debe plantearse el tema de su reforma. El criterio referencial debe ser, pues, no tanto hacerlos más eficientes neutralmente sino hacerlos más eficientes en relación con el despliegue de esas posibilidades.

Las propuestas de potenciación de los Parlamentos con esa finalidad concreta, deben mirar no sólo al interior sino al exterior de los mismos, para tratar de convertirlos en instrumentos más sensibles y capaces respecto de las acciones que tienen lugar fuera de los Parlamentos.

De acuerdo con ello, los iniciales objetivos para un reforzamiento, en el sentido de referencia, de la acción parlamentaria e inspiradores de las correspondientes medidas, podrian ser los siguientes:

- Defensa de la legalidad, del monopolio de la función legislativa por parte del Parlamento y en general de los presupuestos del Estado de Derecho. No sólo por las razones que apunta Ferrajoli y cuyo fundamento consideramos antes y que se refieren a su contribución fuertemente disfuncional al sistema respecto del que puede decirse que, de nuevo, wla legalidad le mata", sino porque es garantía de los derechos y libertades, elementos indispensables para toda acción organizada y porque es el instrumento adecuado para consolidar (legalizar) los posibles logros obtenidos por la acción desarrollada fuera del Parlamento.

Para ello podrán arbitrarse los medios adecuados que permitieran un detenido estudio del tema de las delegaciones al Ejecutivo (¿comisión de delegación?), considerando, a su vez, las posibilidades alternativas que podrá ofrecer la "descentralización" de la función legistativa en órganos locales.

- Considerar de la mayor importancia el control extraparlamentario del Parlamento y las posibilidades legitimadoras de éste, lo que debe traducirse en una revalorización y fortalecimiento de todo lo que se relacione con las discusiones parlamentarias, la publicidad de las sesiones y con la exigencia de una mayor información de los Parlamentos hacia la sociedad. En relación con este aspecto la propuesta de Chimenti de que los Parla- 
mentos cuenten con sus propios medios de comunicación, no parece inoportuna.

Asimismo, es desde esta virtualidad legitimadora de los Parlamentos, desde la que habría que considerar el tema de las comisiones y la atribución de sus competencias, más que desde la exclusiva perspectiva de la racionalidad técnica.

- Reforzar las funciones de control económico tanto en materia presupuestaria como a través de una globalización legislativa de toda la política económica, evitando en lo posible tanto la legislación coyuntural y concreta como la fuga de reales competencias legislativas a través de los convenios que se realicen entre las organizaciones socioeconómicas (patronal-sindicatos), integrándose a éstos en aquel proyecto global. En este orden merecería especial atención articular la relación entre el Parlamento y el Tribunal de Cuentas de forma que éste suministrase al Parlamento una información no sólo suficiente sino estructurada y coherente del resultado de la intervención estatal y del gasto público.

-Favorecer y potenciar el acceso directo y no a través del Gobierno, del Parlamento a la información así como sus facultades de inspección y control de la Administración, sin límite de materias reservadas, militares, etc. Todo ello evidentemente supone el correspondiente equipamiento técnico del Parlamento.

-Establecer mecanismos que aseguren la eficacia de las decisiones del Parlamento y su cumplimiento por el Gobierno mediante comisiones de seguimiento tanto de la aplicación y cumplimiento de las leyes como del resto de las resoluciones, estableciéndose, en su caso, la correspondiente responsabilidad. Ello obligaría, por otra parte, a modificaciones importantes en el trabajo parlamentario tendentes a conseguir que su expresión final fuera suficientemente concreta como para que aquellas decisiones se configuraran como "normas de comportamiento" del Gobierno (F. Fabri).

- Hacer real la autonomía del Parlamento en los diferente ámbitos, desde el de la disponibilidad de medios hasta la del tiempo de trabajo evitando tanto su reducción como su control por el Gobierno, cuestión nada desdeñable, pues, como se ha señalado con acierto, constituye hoy una de las vias más insidiosas contra los Parlamentos la disminución relativa de su tiempo de trabajo así como el dominio que de él tiene el Gobierno(56). 
(1) Aqui se parte, como supuesto previo, de que los Parlamentos modernos surgen a partir de las Revoluciones burguesas, en abierta ruptura con las Asambleas medievales, porque tanto los fundamentos teóricos de unos y otras como la distinta función que realizan, las definen co. mo instituciones de distinta naturaleza y función como corresponde a su respectiva situación en modos distintos de producción.

(2) Vid. G. JELLINEK, Teoría General del"Estado, Ed. Albatros, Buenos Aires, 1.964, pp. 429 y ss., 440 y ss. y 501 y ss. 1.075 .

(3) R. CARRE DE MALBERG, Teoria General del Estado, F.C.E., México, 1.949, pp. 904 a y 154.

(4) H. KELSEN, Esencia y valor de la Democracia, Editora Nacional, Madrid, 1.980, pp. 133

(5) C. MARX, Crítica de la Filosofia del Estado de Hegel, Grijalvo, 1.961, pp. 139 y ss.

(6) Vid. G. DE LA VOLPE, ROUSSEAU Y MARX, Ed. Platina, Buenos Aires, 1.963, y D. GUERIN, La lutte de classes sous la Premiere Republique 1.793-1.797, Gallimard, 1.968 (nouvelle edition), Vol. I, pp: 37 y ss.

(7) E. FORSTHOFF, El Estado de la sociedad industrial, L.E.P., Madrid, 1.975, pp.155 y ss.

(8) T. MARTINES, Governo Parlamentare e Ordinamento Democratico, Giuffré, Milano, 1.967, Introduzione.

(9) La tan celebrada aportación de Bobbio ignora interesadamente el tema ya que es la premisa, que acepta acríticamente, sobre la que basa su posición; por eso resulta demoledora la respuesta de Ferrajoli, mucho menos celebrada, al cuestionarla. Vid. L. FERRAJOLI, Esiste una democrazia rappresentativa?, Unión proletaria, Marzo, 1.978.

(10) Sobre todo en Italia a propósito de la crisis del Partido de la mayoría. Vid. La sinistra davantti alla crisi del Parlamento, varios autores, Giuffré, Milano, 1.977.

(11) L. ZAMPETTI, Democracia y poder de los Partidos, Ediciones Iberoamericanas, 1.970, pp. 37 y ss.

(12) S. LABRIOLA, Parlamento, Instituzioni, Democrazia, Giuffré, Milán, 1.980, p. 7.

(13) Ibid. pp. 38 a 44.

(14) Ibid. pp. 11 y 6.

(15) Ibid. pp. 12 y ss.

(16) ENZO CHELI y CARLO MACCHITELLA, L'áttivitá conoscitiva delle camera, en Parlamento, cit., pp. 36 y 37 .

(17) S. LABRIOLA, cit. pp. 36 y 37.

(18) Hacia una teoria politica del capitalimo periférico, en H. R. SONNTAG y H. VALECILLOS, El Estado en el capitalismo contemporáneo, Ed. Siglo XXI, México, 1.977. ss.

(19) TILMAN EVERS, El Estado en la periferia capitalista, Siglo XXI, México, 1.979, pp. 97 y

(20) Vid. H. ALAVI, El Estado en las sociedades poscoloniales: Pakistán y Bangladesh, en El estado en el capitalismo contemporáneo, cit.

(21) Lo que, por otra parte, no ha dejado de ser frecuente incluso desde el interior de este tipo de sociedades. Así vid. J. J. BUSTOS RAMIREZ, La problemática del Estado en Latinoaméri- 
ca, en la lucha por la democracia en América Latina, Universidad Menéndez y Pelayo, Ministerio de Educación y Ciencia, 1.981.

(22) C. DE CABO, Aproximación teórica al momento politico y jurídico español, Rev. de Es'tudios Políticos, 1.981.

(23) K. OFFE, The abolition of market control and the problem of legitimacy, Kapitalistate, n.०1 y 2.

(24) N. POULANTZAS, Estado, poder y socialismo, Siglo XXI, Madrid, 1.979, pp. 207 y ss.

(25) P. DE VEGA, Estudios políticoconstitucionales, Universidad Autónoma de México, 1.980, p. 193.

(26) G. F. HEGEL; Principios de la Filosofia del Derecho, Edit. Sudamericana, Buenos Aires, 1.975 , pp. 318,355 y ss.

(27) N. BOBBBlO y otros, La sinistra davanti alla crisi del Parlamento, Giuffré, Milano, 1.977, pp. $21,22,23$ y ss.

(28) P. BIRNBAUM, Les nouvelles fonctions du Parlament dans la France contemporaine, en Parlamento y sociedad civil, Universidad de Barcelona, 1.980, pp. 107 y ss.

(29) Vid. L. FERRAJOLI, Esiste una democrazia rappresentativa, Unitá Proletaria, Marzo, 1.978 , pp. 48 y 49.

(30) J. HABERMANS, Concepto de participación politica, en Capital monopolista y sociedad autoritaria, Ed. Fontanella, Barcelona, 1.973,'p. 26.

(31) MANCELA, ì Parlamento, II Mulíno, Bologna, 1.973, p. 265; en el mismo sentido P. AVRIL afirma, réfiriéndose al Parlamento francés, que el gobierno disfruta de un monopolio total en la dirección del trabajo parlamentario en virtud del art. 43 de la Constitución que concede prioridad a los textos presentados o aceptados por el Gobierno. Este art.-dice-es más importante aunque menos espectacular que el discutido art. 34 que concede al Gobierno una cláusula de competencia general (Le Parlament legislateur, R.F.S.P., Febrero, 1.981, p. 16).

(32) Vid. FERRAJOLI, cit.

(33) U. CERRONI, La regole Costituzionali della democrazia política, en Democracia e Diritto, n. ${ }^{\circ}$ 1, Marzo, 1.978.

(34) MAX WEBER, Economia y Sociedad, F.C.E., Méjico, pp. 1.111 y 1.112.

(35) PERRY ANDERSON, Las antinomias de A. GRAMSCI, Ed. Fontamara, 1.978, p. 72.

(36) Ibidem, p. 53.

(37) J. AGNOLI y P. BRUCKNER, La transformación de la Democracia, Siglo XXI, Méjico, $1.971, \mathrm{pp} .67$ y ss.

(38) En "Towards Socialism» (Problems of socialism strategy) Collins, Glasgow, 1.966.

(39) L. FERRAJOLI, 'cit.

(40) El 18 de Brumario, Ariel, Barcelona, 1.971, p. 141.

(41) Vid. M. CAMPANELLA, Marx e la disoluzione dello Stato. II potere legisiativo, en Stato : e Teorie marxiste, Mazzota, Milano 1.977.

(42) F. ENGELS, Introducción a la lucha de clases en Francia, Edit. Claridad, Buenos Aires, 1.973, p. 25.

(43) F. ENGELS, El origen de la familia, Editorial Fundamentos, Madrid, 1.970, p. 215.

(44) . La enfermedad infantil del izquierdismo en el comunismo, Ed. en Lenguas extranjeras, Pekin, 1.968 , pp. 49 y ss.

(45) El Estado y la Revolución, Ed. en Lenguas extranjeras, Pekin, 1.978, pp. 86 y 98. 
(46) Vid. AGNOLI, cit., pp. 5 y ss.

(47) Ibidem.

(48) C. B. GLUCKSMAN, Crisis de la idea de Revolución, en Vias democráticas al socialişmo, Ayuso, Madrid, 1.981, p. 172. a 41.

(49) .L. MAGRI, Via Parlamentaria o via Consejista, Edit. Anagrama, Barcelona, 1.977 pp. 6

(50) J. BERNARDO, Para una teoría del modo de producción comunista, Ed. Zero-Zyx, Madrid, 1.977, pp. 17 y ss.

(51) Vid. C. U. SCHUMINCK-GUSTAVUS, El Renacimiento del Leviatan, Fontanella, BarceIona, 1.982, pp. 59 y 60.

(52) G. HODGSON, Socialismo y Democracia parlamentaria, Ed. Fontamara, Barcelona, 1.980 , p. 60 y ss.

(53) Idem, p. 109.

(54) Vid. Varios autores, Vías democráticas al socialismo, cit., pp. 225 y ss. Resulta significativo que no se plantee el tema de la articulación entre la acción extraparlamentaria y parlamentaria.

(55) G. NOVACK y J. HANSEN, Introducción al Programa de la transición, Ed. Fontamara, Barcelona, 1.978, p. 66.

(56) CLAUDE GIBEL, L'evolution des moyens de travail des parlamentaires, R. F. S. P., Febrero 1.981, pp. 221 y ss. 